\title{
Estimation of Average Crystallites Size of Active Phase in Ceria- Supported Cobalt-Based Catalysts by Hydrogen Chemisorption vs TEM and XRD Methods
}

\author{
Grzegorz Słowik $^{1}$ - Anna Gawryszuk-Rżysko ${ }^{2}$ Magdalena Greluk ${ }^{1}$. \\ Andrzej Machocki ${ }^{1}$
}

Received: 10 June 2016 / Accepted: 5 August 2016 / Published online: 18 August 2016

(C) The Author(s) 2016. This article is published with open access at Springerlink.com

\begin{abstract}
Cobalt catalysts with $\mathrm{CeO}_{2}$ support, unpromoted and promoted with potassium were prepared by an impregnation method. Reduced catalysts were subjected to hydrogen chemisorption at different temperatures in the range of 313-453 K. Studies have shown that calculated Co crystallites size depends on the temperature of chemisorption. The average of size crystallites of the Co active phase obtained from the total and strong chemisorption data were compared with those from measurements by other techniques, TEM and XRD. The results of comparison allowed us to indicate the most suitable chemisorption temperature, different for unpromoted $(383 \mathrm{~K})$ and potassium-promoted $(413 \mathrm{~K})$ catalysts to determine the proper Co crystallites size of active phase, compatible with the crystallites size determined by the most objective method, i.e. by TEM measurements. In the case of small metal crystallites of active phase (4-5 nm) the divergence of their average size determined by hydrogen chemisorption and TEM methods and particularly by the XRD method is definitely higher than that in the case of larger crystallites $(\sim 12 \mathrm{~nm})$.
\end{abstract}

Electronic Supplementary Material The online version of this article (doi:10.1007/s10562-016-1843-1) contains supplementary material, which is available to authorized users.

Grzegorz Słowik

Grzegorz.Slowik@poczta.umcs.lublin.pl

1 Department of Chemical Technology, Faculty of Chemistry, University of Maria Curie-Sklodowska, 3 Maria CurieSklodowska Square, 20-031 Lublin, Poland

2 Faculty of Chemistry, Analytical Laboratory, University of Maria Curie-Sklodowska, Lublin, Poland
Graphical Abstract

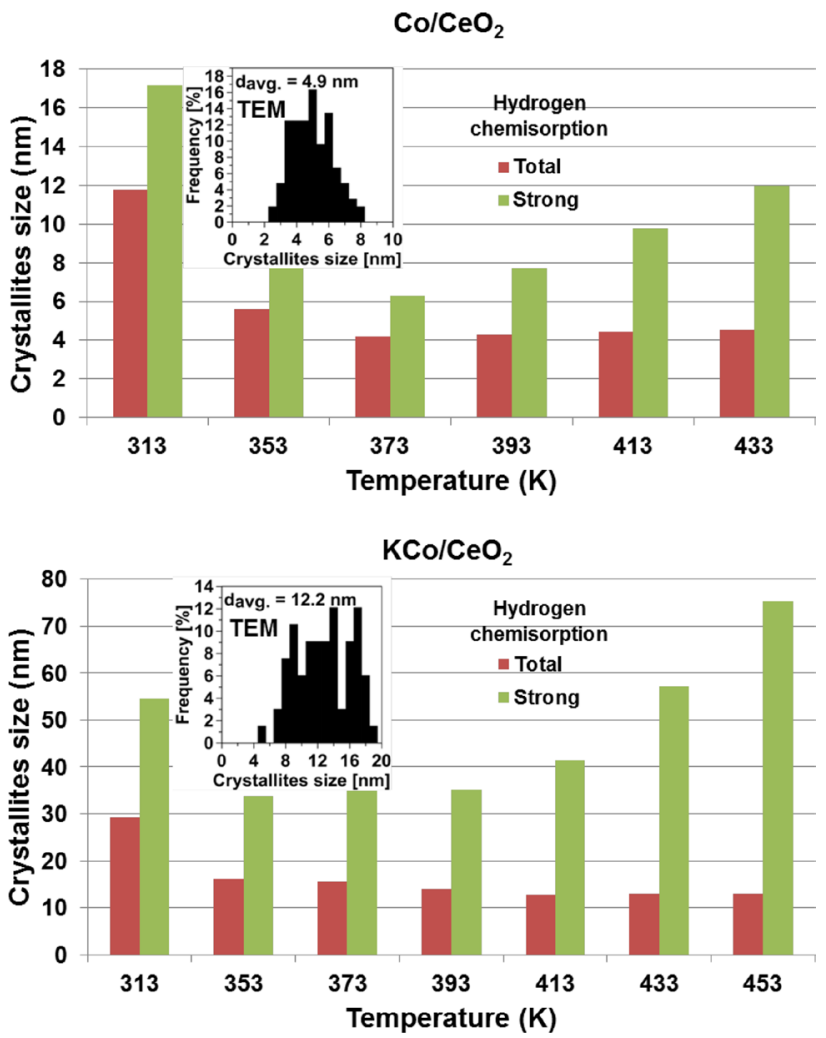

Keywords Heterogeneous catalysis .

Electron microscopy $\cdot$ Nanostructure $\cdot$ Crystallites size Hydrogen chemisorption $\cdot$ XRD $\cdot$ Cobalt-based catalysts 


\section{Introduction}

Heterogeneous catalysts through their irreplaceable role in chemicals and fuels production constitute a high interest research topic [1]. In such catalytic processes as the steam reforming of ethanol (SRE) [2] or the Fischer-Tropsch synthesis (FTS) [3, 4], besides operating conditions, the use of suitable catalyst plays a crucial role in achieving selective, efficient and economically profitable process $[2,5,6]$. The commonly used in the FTS or proposed for the SRE heterogeneous catalysts are cobalt-based ones [2-7], usually highly dispersed on inorganic oxide supports [8], which show a high activity and stability, relatively low cost and a high selectivity for the most desirable reaction products [9]. Among supports of the active phase, cerium oxide was used very often in various catalytic systems $[3,10,11]$. Ceria is characterized by a high oxygen transport and its storage capacity, by shifting between $\mathrm{Ce}^{3+}$ and $\mathrm{Ce}^{4+}$ under reductive-oxidative conditions $[12,13]$. Due to these properties, cerium oxide shows a high affinity for $\mathrm{H}_{2}$ and $\mathrm{CO}$ molecules [3], and thereby, an activity in various catalytic reactions such as water gas shift, oxidation of hydrocarbons or oxidation of CO $[10,13]$. Ceria is also widely used in supported catalysts proposed to the SRE [14-16].

The catalytic properties of catalysts depend on their key parameters, such as crystallites size, structure and morphology [17]. Dispersion (and the average size) of the metallic active phase is one of the most important parameters characterizing the heterogeneous catalysts [8], which are essential for the activity, selectivity and stability of catalytic processes. The catalytic activity of a supported catalysts depends on the degree of dispersion of the metallic active phase and its active surface area $[8,18]$, and it usually increases with increasing dispersion of metal and decreasing its crystallites size [18]. On the other hand, the crystallites shape and their size distribution are important for mechanism of catalytic reaction, which dependents on the crystal faces exposed at the surface [19].

The crystallites size of metallic active phase are usually determined by hydrogen chemisorption, X-ray diffraction (XRD) or TEM (Transmission Electron Microscopy) [8, 17, 20-22], but sometimes different results are found from various methods for the same catalyst. The differences in measurements of the crystallites size can result from methods limitation. In the case of various active phases, limitations of the XRD measurements can result from the fact that XRD does not measure the smallest particles. The measurement limitations can also concern hydrogen adsorption capacity which can be diminished by strong metal-support interactions [9].

The evaluation of dispersion of the active phase, on the basis of hydrogen chemisorption data is a common, simple and cheap method. However, literature show that temperature of hydrogen chemisorption measurements can significantly influence on obtained results. More than 40 years ago Bartholomew et al. [23-25] show that the chemisorption of hydrogen over cobalt catalysts with various supports $\left(\mathrm{SiO}_{2}, \mathrm{Al}_{2} \mathrm{O}_{3}, \mathrm{C}, \mathrm{MgO}, \mathrm{ZSM}-5, \mathrm{TiO}_{2}\right)$ and over unsupported cobalt is activated and highly reversible. The activation was a function of the interaction of cobalt with a support or promoter. Frequently used in catalysis, potassium promoter significantly increased the adsorption activation energy for hydrogen [26]. It is also proved that some methods for determining the hydrogen uptake, i.e. flow adsorption methods such as thermal desorption and pulse methods, measure only irreversible (strong) chemisorption $[23,27]$. No hydrogen desorption was detected for MgOand ZSM-5-supported and low-loaded (1-3 wt.\%) aluminasupported cobalt catalysts using TPD method, even though those catalysts adsorbed hydrogen when the static technique was applied $[23,24]$. The special case is the $\mathrm{Co} / \mathrm{TiO}_{2}$ system, where due to the strong metal-support interactions the stoichiometry of hydrogen chemisorption is lower than one hydrogen atom per surface cobalt atom, even in static measurements. With exception of the cobalt systems in which the strong metal-support interactions take place, the static technique was recommended for estimation of the average size of cobalt crystallites on the basis of maximal hydrogen chemisorption uptake, usually at $373 \mathrm{~K}$. A good correlation with TEM measurements was found for the $\mathrm{Co} / \mathrm{SiO}_{2}, \mathrm{Co} / \gamma-\mathrm{Al}_{2} \mathrm{O}_{3}$ and $\mathrm{Co} / \mathrm{C}$ catalysts. The paper [9] also shows that the volume of chemisorbed hydrogen (including strong and weak chemisorption) on the $\mathrm{CoRe} / \gamma-\mathrm{Al}_{2} \mathrm{O}_{3}$ catalyst varies with the temperature of chemisorption, and the use of different data leads to the determination of different average size of crystallites, even though the actual crystallites size remains unchanged. They obtained the best results when the total chemisorption uptake measured at $373 \mathrm{~K}$ was used for cobalt dispersion calculation. In the current literature, there is a large discrepancy between conditions and a manner of hydrogen chemisorption measurements, from which data are used to determine the average size of crystallites and dispersion of the metallic cobalt phase deposited on an oxide support. Although those, already old, recommendations, only in the 2015-beginning of 2016 period the much lower temperature, 293-323 K, of hydrogen chemisorption [28-37] and flow adsorption pulse and TPD methods [32-37] are used in many laboratories. The higher, $423 \mathrm{~K}$, temperature of hydrogen chemisorption was also applied in the pulse method for estimation of the average size of cobalt crystallites [33].

From three methods (hydrogen chemisorption, TEM and XRD) used for crystallites size determination, only TEM shows distinct advantages for the direct measurement of crystallites size in comparison with other methods, because the metal active phase crystallites can be quite clearly distinguished from the catalyst support and directly measured. Additionally to the crystallite diameters measurement, TEM 
allows determining of crystallites size distribution and also to carry out morphological characteristics of crystallites, such as the shape and the structure [25].

The aim of this work is determination of the optimum temperature for hydrogen chemisorption and evaluation of correctness of the use of the total and strong chemisorption data to determine of the average size of cobalt-based active phase crystallites, supported on ceria. There was not previously shown whether, and to what extent, this support oxide, having a special previous mentioned properties, influences activation of hydrogen chemisorption and what the chemisorption temperature is necessary to obtain the average size of cobalt crystallites the most compatible with the crystallites size determined by the most objective transmission electron microscopy method (taking into account a statistically high number of crystallites measured). The influence of potassium promoter of ceria-supported cobalt-based catalyst on the optimal for this application hydrogen chemisorption temperature will be also determined. The results obtained by these two methods will be compared also with the values of the average size of crystallites obtained by the X-ray diffraction method.

Crystallites size of the cobalt-based active phase will be determined in the ceria-supported cobalt catalysts in which the active phase was promoted/unpromoted with 2 wt. \% of potassium. Such catalysts are considered for the use in the SRE for production of hydrogen-rich gas for fuel cells fuelling.

\section{Experimental}

\subsection{Catalyst Preparation}

The $\mathrm{Co} / \mathrm{CeO}_{2}$ and $\mathrm{KCo} / \mathrm{CeO}_{2}$ catalysts were prepared by twostep impregnation of cerium oxide support. Prior to the impregnation ceria (Aldrich) was dried at $383 \mathrm{~K}$ for $3 \mathrm{~h}$. For the first impregnation an aqueous solution of cobalt nitrate with citric acid $\mathrm{CA}(\mathrm{Co} / \mathrm{CA}=1 / 1 \mathrm{~mol} / \mathrm{mol})$ were used. For the second impregnation, for the K-promoted catalyst an aqueous solution of potassium nitrate was used. After each impregnation, the catalyst precursor was dried at $383 \mathrm{~K}$ for $12 \mathrm{~h}$, then calcined at $673 \mathrm{~K}$ with the heating rate of $2.2 \mathrm{~K} / \mathrm{min}$ up to the calcination set point and maintained for $1 \mathrm{~h}$ at this temperature. Before all measurements the catalysts were reduced with hydrogen at $673 \mathrm{~K}$ for $1 \mathrm{~h}$. The in situ XRD measurements confirmed complete reduction of cobalt oxide to metallic cobalt.

\subsection{Hydrogen Chemisorption}

Hydrogen adsorption isotherms were measured in a standard, commercial volumetric apparatus (Micromeritics, ASAP 2020C). The reactor was loaded with $0.9 \mathrm{~g}$ of the catalyst. Prior to the measurements, the catalysts were in-situ reduced in flowing hydrogen with the temperature programmed from ambient to $673 \mathrm{~K}$ with the heating rate of $10 \mathrm{~K} / \mathrm{min}$. The $673 \mathrm{~K}$ temperature was maintained for $1 \mathrm{~h}$. After reduction, the samples were evacuated for $2 \mathrm{~h}$ at the reduction temperature. Then, under the vacuum of $3.8 \times 10^{-7} \mathrm{~Pa}$, the catalyst samples were cooled down to the temperature of chemisorption. Hydrogen chemisorption isotherms were measured in the range of 313433 or $453 \mathrm{~K}$ and in the pressure range of $15-475 \mathrm{mmHg}$. Subsequently, the sample of catalyst was evacuated for $30 \mathrm{~min}$, keeping the constant temperature (the same at which the first isotherm was taken), and the second isotherm of weak chemisorption was recorded. The strong chemisorption isotherm of hydrogen was calculated as a difference of the first (total) and the second (weak) isotherms. For measurements of the chemisorption isotherms at various temperatures always the new catalyst sample was used. The uptake of hydrogen (total, weak and strongly chemisorbed) was determined by extrapolating the straight-line portion of isotherms to zero pressure. The surface area of the cobalt active phase was calculated assuming a commonly used chemisorption stoichiometry $\mathrm{Co}: \mathrm{H}=1: 1[25$, 27 ] and the surface area occupied by one atom of hydrogen equal to $0.065 \mathrm{~nm}$ [27]. The average size of cobalt crystallites was calculated assuming their spherical (or semi-spherical) shape, from the common Eq. (1):

$\mathrm{d}=6 \cdot 10^{3} /\left(\mathrm{d}_{\mathrm{Co}} \cdot \mathrm{S}_{\mathrm{Co}}\right)$

where $\delta_{\text {Co }}$ is the density of cobalt $\left(\mathrm{g} / \mathrm{cm}^{3}\right)$ and $\mathrm{S}_{\mathrm{Co}}$ is the surface area of cobalt $\left(\mathrm{m}^{2} / \mathrm{g}_{\mathrm{Co}}\right)$.

\subsection{TEM Measurements}

The catalysts (fresh, oxide form) were grinded in an agate mortar to fine powders. The resulting powder of each catalyst was poured with $99.8 \%$ ethanol (POCH) to form slurry which subsequently was inserted into a ultrasonic homogenizer for $20 \mathrm{~s}$. Then, the catalyst-containing slurry was pipetted and supported on a 200 mesh copper grid covered with lacey formvar and stabilized with carbon (Ted Pella Company) and left on a filter paper for ethanol evaporation. The samples deposited on the grid were inserted to a singletilt holder and moved to the electron microscope.

The catalysts reduced in a fixed-bed reactor with hydrogen flow rate of $100 \mathrm{ml} / \mathrm{min}$ at $673 \mathrm{~K}$ were transferred in a closed reactor to a glovebox. The reactor was opened and the catalyst was prepared for TEM measurements in the glovebox filled with argon (it protected the catalyst from oxidation), and applied to the copper grid covered with lacey formvar and stabilized with carbon. Next, the each catalyst deposited on the grid was inserted into the vacuum transfer holder (Gatan); the holder was closed and the catalyst was transferred in argon atmosphere to the microscope. The high-resolution electron microscope Titan G2 60-300 kV (FEI Company), equipped with: the field emission gun 

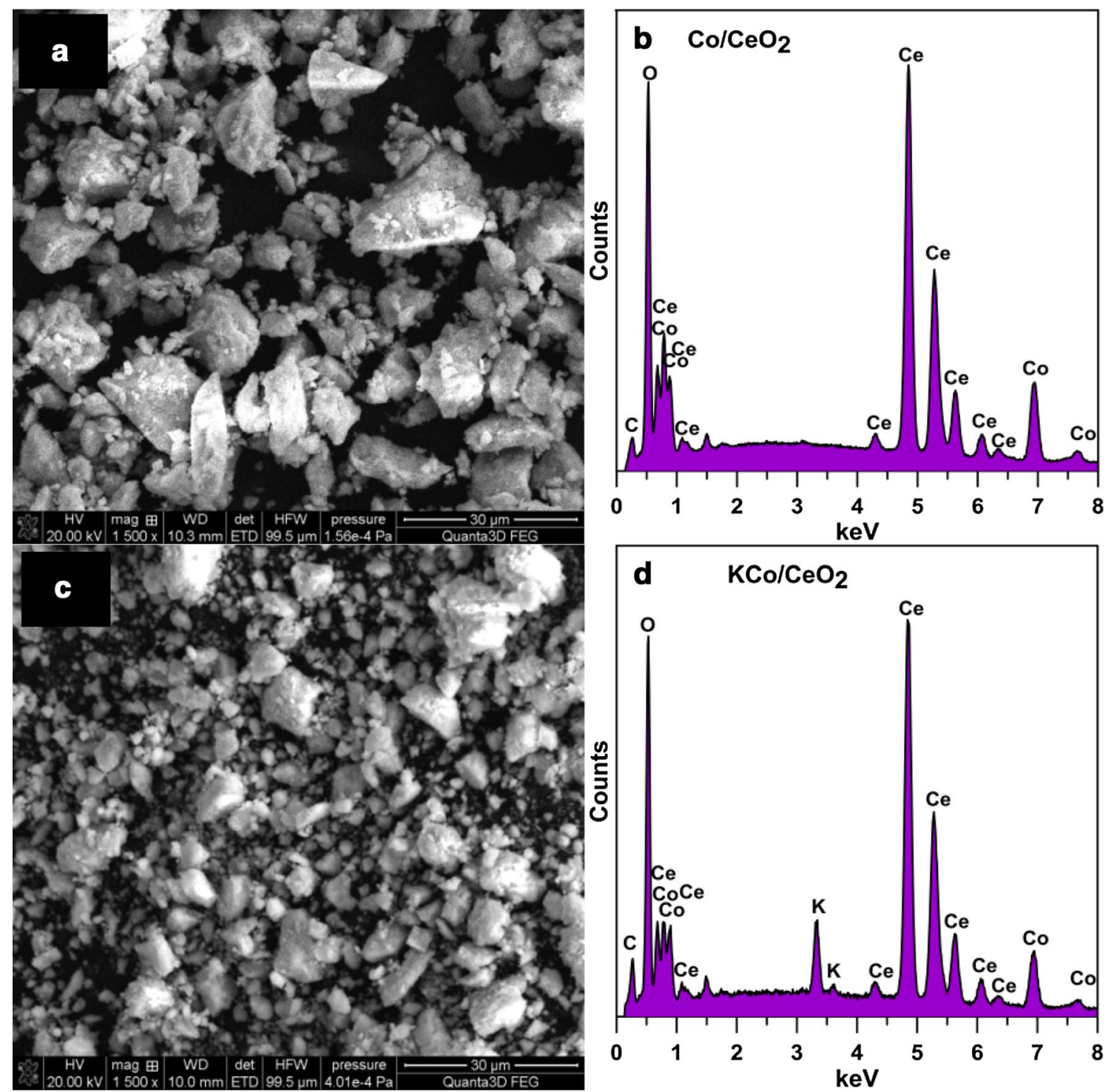

Fig. 1 SEM images and qualitative EDS spectra of $(\mathbf{a}, \mathbf{b}) \mathrm{Co} / \mathrm{CeO}_{2}$ and $(\mathbf{c}, \mathbf{d}) \mathrm{KCo} / \mathrm{CeO}_{2}$ catalysts

Table 1 Quantitative EDS analysis of main elements in $\mathrm{Co} / \mathrm{CeO}_{2}$ and $\mathrm{KCo} / \mathrm{CeO}_{2}$ catalysts

\begin{tabular}{|c|c|c|c|c|}
\hline \multirow[t]{2}{*}{ Element } & \multicolumn{2}{|l|}{$\mathrm{Co} / \mathrm{CeO}_{2}$} & \multicolumn{2}{|l|}{$\mathrm{KCo} / \mathrm{CeO}_{2}$} \\
\hline & Wt.\% & At. $\%$ & Wt.\% & At. $\%$ \\
\hline Co & $9.44 \pm 0.29$ & $9.18 \pm 0.24$ & $8.83 \pm 0.33$ & $8.47 \pm 0.86$ \\
\hline K & - & - & $2.16 \pm 0.40$ & $3.18 \pm 0.47$ \\
\hline
\end{tabular}

(FEG), monochromator, three condenser lenses system, the objective lens system, image correction $\left(\mathrm{C}_{\mathrm{s}}\right.$-corrector $)$, HAADF detector and EDS spectrometer (Energy Dispersive X-ray Spectroscopy) was used to display the catalysts. Microscopic studies of the catalysts were carried out at an accelerating voltage of the electron beam equal to $300 \mathrm{kV}$ for the catalysts in the oxide and reduced forms.
The elements mapping was carried out in the STEM mode by collecting point by point EDS spectrum of each of the corresponding pixels in the map. The collected maps were presented in the form of a matrix of colored pixels with the intensity corresponding to the amount of the element.

The size and shape of the particles in the fresh and reduced $\mathrm{Co} / \mathrm{CeO}_{2}$ and $\mathrm{KCo} / \mathrm{CeO}_{2}$ catalysts were determined by using the high resolution TEM (HRTEM) imaging and FFT. Phase separation (crystal lattice of the cerium oxide and crystal lattice of the active phase-for better distinguishing of support and active phase crystallites) was performed with the FFT by using a masking available in the Gatan DigitalMicrograph software package. On the basis of the FFT generated from HRTEM images of the fresh and reduced catalysts, individual phases with various crystallographic orientation derived from ceria support and as well 
Fig. 2 a HRTEM images,

b phase identification, c

cobalt-based crystallites size

measurements example and $\mathbf{d}$

cobalt-based crystallites size

distributions in the fresh (in the oxide form) $\mathrm{Co} / \mathrm{CeO}_{2}$ and $\mathrm{KCo} /$ $\mathrm{CeO}_{2}$ catalysts
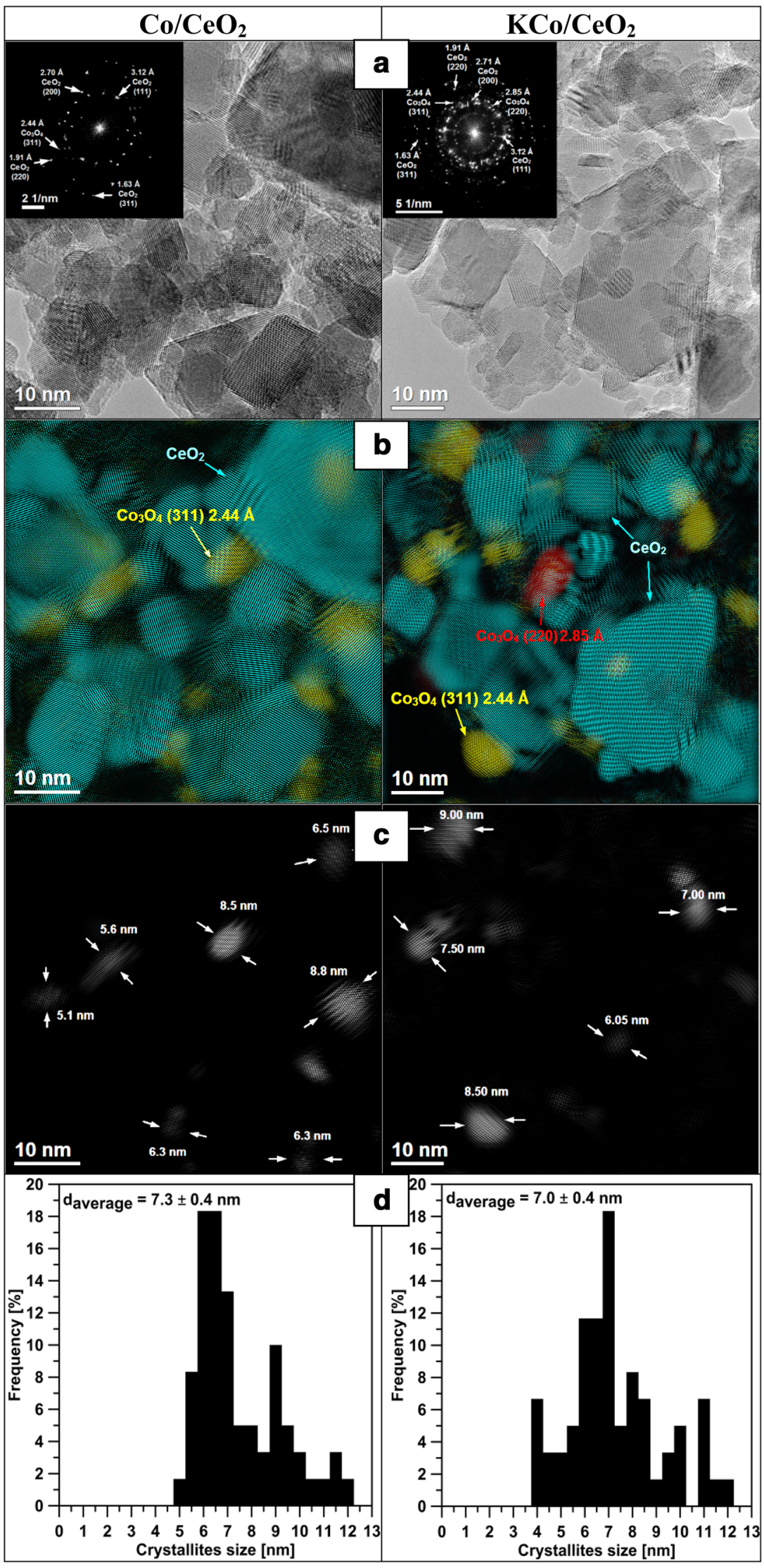
a
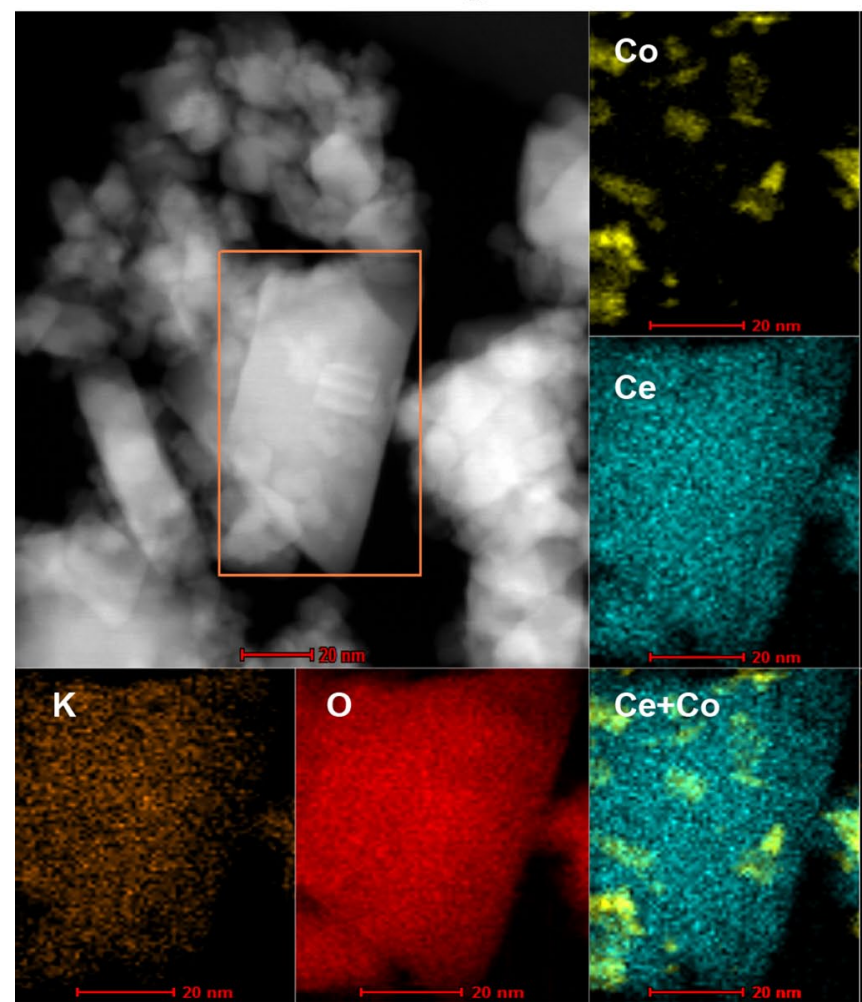

b

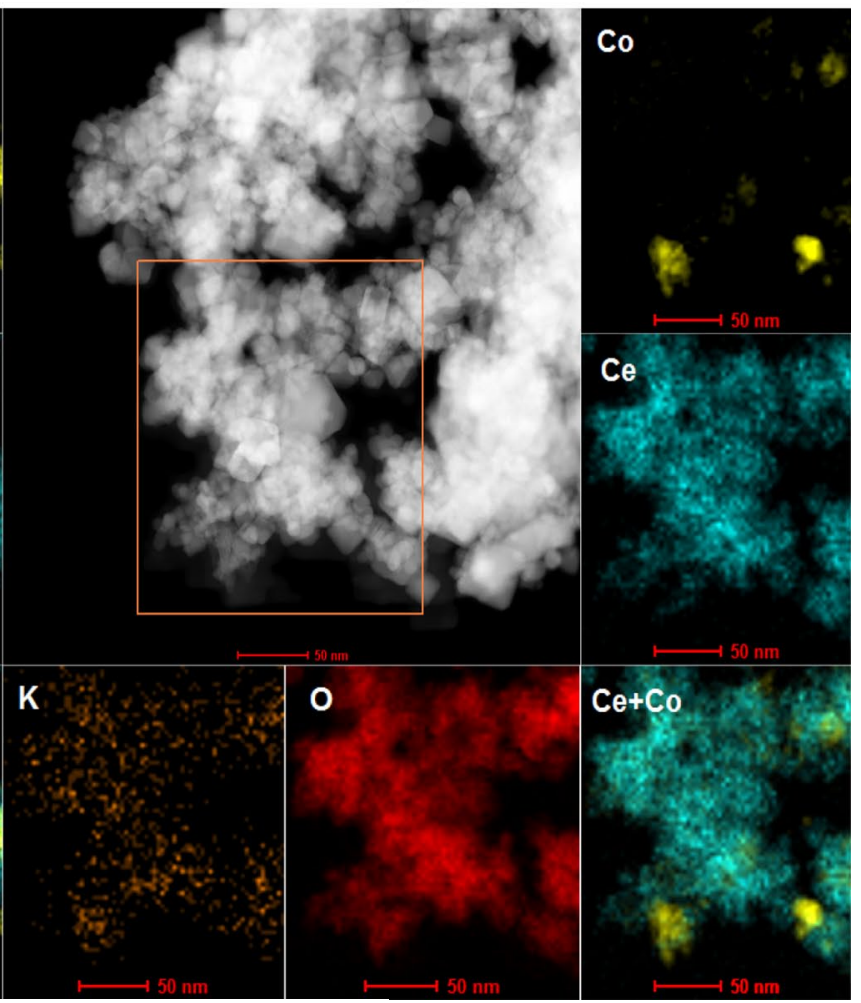

Fig. 3 STEM-EDS analysis of a the fresh (in the oxide form) and $\mathbf{b}$ the reduced $\mathrm{KCo} / \mathrm{CeO}_{2}$ catalyst

as active phase in various forms, $\mathrm{Co}_{3} \mathrm{O}_{4}$ (oxide) and $\mathrm{Co}^{0}$ (reduced), respectively were identified. Then, the mask was imposed on the FFT in order to separate crystallites of the active phase $\left(\mathrm{Co}_{3} \mathrm{O}_{4}\right.$ or $\left.\mathrm{Co}^{0}\right)$ from crystallites of the support present on the HRTEM images. The measurements of the size of separated crystallites of the active phase allowed us to determine distribution of crystallites size. Particle size distribution was obtained by measuring diameter of about 150 particles for all TEM measurements. The average size of particles was then calculated from the Eq. (2):

$$
\mathrm{d}_{\text {average }}=\sum \mathrm{N}_{\mathrm{i}} \mathrm{D}_{\mathrm{i}} / \sum \mathrm{N}_{\mathrm{i}}
$$

where: $\mathrm{N}_{\mathrm{i}}$ - the numbers of metal crystallites in a specific size range, $D_{i}-$ the average diameter in each diameter range.

Qualitative and quantitative contents of main elements in the catalysts were determined from EDS spectra collected by using the FEI Quanta 3D FEG scanning electron microscope, equipped with the EDS spectrometer.

\subsection{XRD Measurements}

Before XRD measurements, the catalysts were in-situ reduced at $673 \mathrm{~K}$ in hydrogen flow rate of $100 \mathrm{ml} / \mathrm{min}$ in the XRK 900 reactor chamber (Anton Paar). X-ray diffraction patterns were collected at two temperatures, at $303 \mathrm{~K}$ for the fresh (oxide) samples and at $673 \mathrm{~K}$ (reduced samples) with Empyrean (PANalytical) X-ray diffractometer, using $\mathrm{CuK} \alpha$ radiation $\left(\lambda=1.54 \times 10^{-10} \mathrm{~m}\right)$. The analyses were recorded in the $2 \theta$ range between $10^{\circ}$ and $110^{\circ}$. For measurements at $303 \mathrm{~K}$ the average crystallites size of cobalt oxide was calculated from the Scherrer equation [38] using the $\mathrm{Co}_{3} \mathrm{O}_{4}$ (311) peak located at $2 \theta=36.8^{\circ}$. The metallic cobalt particles size in reduced catalysts was also calculated from Scherrer formula using the Co (002) peak located at $2 \theta=44 \cdot 3^{\circ}$. A standard crystal of cerium oxide was used as a reference material for determination of the instrumental line broadening.

\section{Results and Discussion}

\subsection{TEM Characterization of Fresh and Reduced Catalysts}

Figure 1 shows SEM images of (a) $\mathrm{Co} / \mathrm{CeO}_{2}$ and (c) $\mathrm{KCo} / \mathrm{CeO}_{2}$ catalysts and qualitative EDS spectra (b and d, respectively), collected from the fresh (in oxide form) catalysts. In Table 1, the percentage of weight and the percentage of atomic contents of main elements in the catalysts obtained from EDS spectra, are shown. Based on quantitative data the following content of cobalt in the fresh $\mathrm{Co} / \mathrm{CeO}_{2}$ catalyst was 
Fig. 4 a HRTEM images,

b phase identification, c

cobalt-based crystallites size

measurements example and $\mathbf{d}$

cobalt-based crystallites size

distributions in the reduced $\mathrm{Co} /$

$\mathrm{CeO}_{2}$ and $\mathrm{KCo} / \mathrm{CeO}_{2}$ catalysts
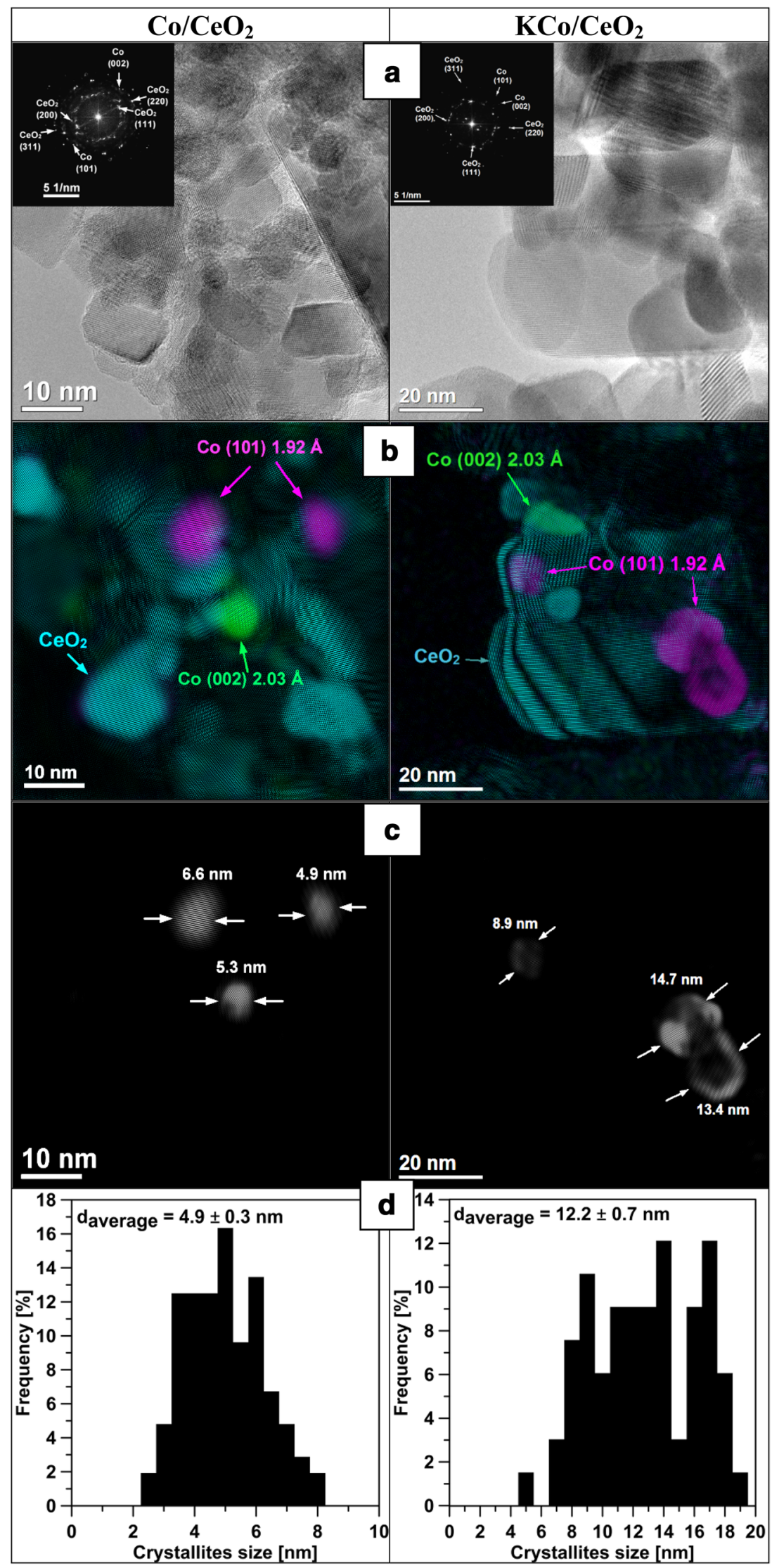

Springer 

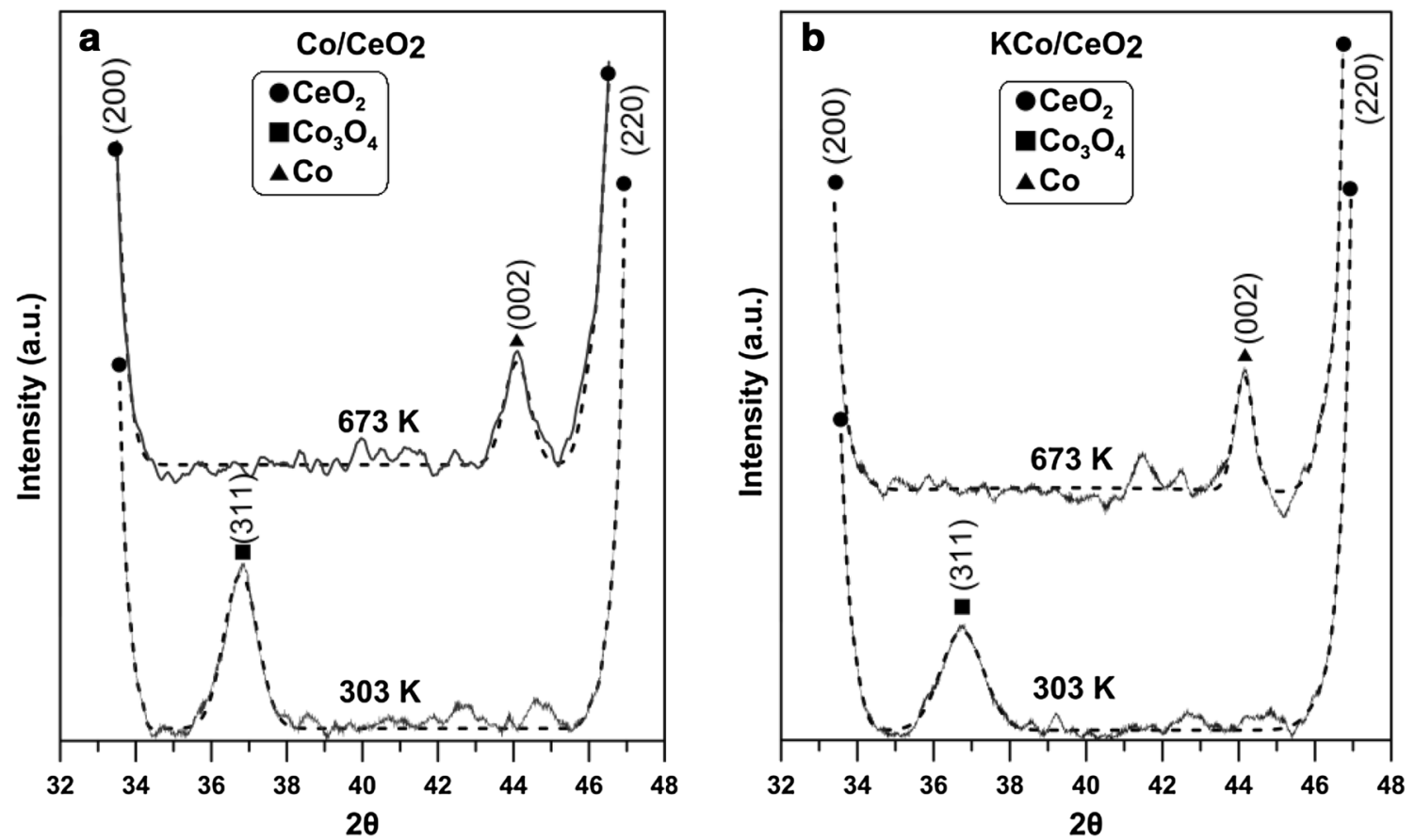

Fig. $5 \mathrm{XRD}$ patterns of $\mathrm{Co} / \mathrm{CeO}_{2}$ and $\mathrm{KCo} / \mathrm{CeO}_{2}$ catalysts performed at $303 \mathrm{~K}$ (fresh, oxide form) and at $673 \mathrm{~K}$ after in situ reduction with hydrogen

Table 2 Comparison of the average size of crystallites determined by TEM, XRD and hydrogen chemisorption for fresh and reduced (at $673 \mathrm{~K}) \mathrm{Co} / \mathrm{CeO}_{2}$ and $\mathrm{KCo} / \mathrm{CeO}_{2}$ catalysts

\begin{tabular}{llrllll}
\hline Catalyst & \multicolumn{2}{l}{ TEM $(\mathrm{nm})$} & & \multicolumn{2}{l}{ XRD $(\mathrm{nm})$} & $\begin{array}{l}\text { Hydrogen } \\
\text { chemisorp- }\end{array}$ \\
\cline { 2 - 3 } & Fresh & Reduced & & Fresh & Reduced & $\begin{array}{c}\text { chon }(\mathrm{nm}) \\
\text { tion }\end{array}$ \\
\hline $\mathrm{Co} / \mathrm{CeO}_{2}$ & $7.3 \pm 0.4$ & $4.9 \pm 0.3$ & & $7.4 \pm 0.4$ & $7.8 \pm 0.4$ & $4.1 \pm 0.3^{*}$ \\
$\mathrm{KCo} / \mathrm{CeO}_{2}$ & $7.0 \pm 0.4$ & $12.2 \pm 0.7$ & & $7.1 \pm 0.4$ & $15.2 \pm 0.8$ & $12.5 \pm 0.3^{* *}$ \\
\hline
\end{tabular}

Measured at $* 383 \mathrm{~K}, * * 413 \mathrm{~K}$

determined: $9.44 \pm 0.29$ wt.\%, and for the fresh $\mathrm{KCo} / \mathrm{CeO}_{2}$ catalyst the following contents of elements were determined: $8.94 \pm 0.28 \mathrm{wt} . \%$ of cobalt and $1.93 \pm 0.10 \mathrm{wt} . \%$ of potassium.

Among of the facets identified on the basis of the FFT in the fresh $\mathrm{Co} / \mathrm{CeO}_{2}$ and $\mathrm{KCo} / \mathrm{CeO}_{2}$ catalysts (Fig. 2), the facets originating from the $\mathrm{CeO}_{2}$ support with interplanar distances $3.12,2.70,1.91,1.63 \AA$ and crystallographic orientations (111), (200), (220), (311) and the facets originating from the active phase in the oxide form $\left(\mathrm{Co}_{3} \mathrm{O}_{4}\right)$ with interplanar distances $2.44,2.85 \AA$ and crystallographic orientations (311), (220) were found. The average crystallites size of the oxide cobalt-based active phase in the unpromoted fresh catalyst was $7.3 \mathrm{~nm}$ while in the K-promoted fresh catalyst this value was equal to $7.0 \mathrm{~nm}$.

STEM-EDS analysis (Fig. 3a) shows a good dispersion of cobalt $(\mathrm{Co}, \mathrm{Ce}+\mathrm{Co}$ maps $)$ and very good dispersion of potassium (K map) in the fresh $\mathrm{KCo} / \mathrm{CeO}_{2}$ catalyst. Similar dispersion of elements (not show here) was found in the K-unpromoted catalyst. Additionally, the EDS map of potassium indicates that it is dispersed both on cobalt and on ceria phases.

The same microscopic measurements were applied to determine phases present in both K-promoted and unpromoted catalysts in their reduced form (Fig. 4). The phase which originates from the support was identified as $\mathrm{CeO}_{2}$ with interplanar distances 3.12, 2.70, 1.91 and $1.63 \AA$ corresponding to the crystal planes (111), (200), (220) and (311), respectively. The cobalt active phase was found as $\mathrm{Co}^{0}$ with interplanar distances 1.92 and $2.03 \AA$ corresponding to the crystal planes (101) and (002), respectively. On the basis of the phases separation generated from the masking process, metallic cobalt was distinguished from the support and its crystallite size distributions was determined for both reduced catalysts. The average size of cobalt-based crystallites in the unpromoted reduced catalyst was $4.9 \mathrm{~nm}$ while in the K-promoted reduced catalyst this value was equal to $12.2 \mathrm{~nm}$. The increase of crystallites size after reduction at $673 \mathrm{~K}$ (from $7.0 \mathrm{~nm}$ for the oxide form to $12.2 \mathrm{~nm}$ for the reduced form) was observed only for the catalyst promoted with potassium. It suggests that the addition of potassium favours sintering of Co crystallites. The reduction of the unpromoted catalyst caused decreasing of the crystallites size from $7.3 \mathrm{~nm}$ (oxide form) to $4.9 \mathrm{~nm}$ (reduced form). The ratio of the average crystallites size (d) of the active phase in reduced form $(\mathrm{Co})$ to the oxidized form $\left(\mathrm{Co}_{3} \mathrm{O}_{4}\right)$ is equal 0.7 for unpromoted catalyst. For K-promoted catalyst this ratio is equal 1.7 . 

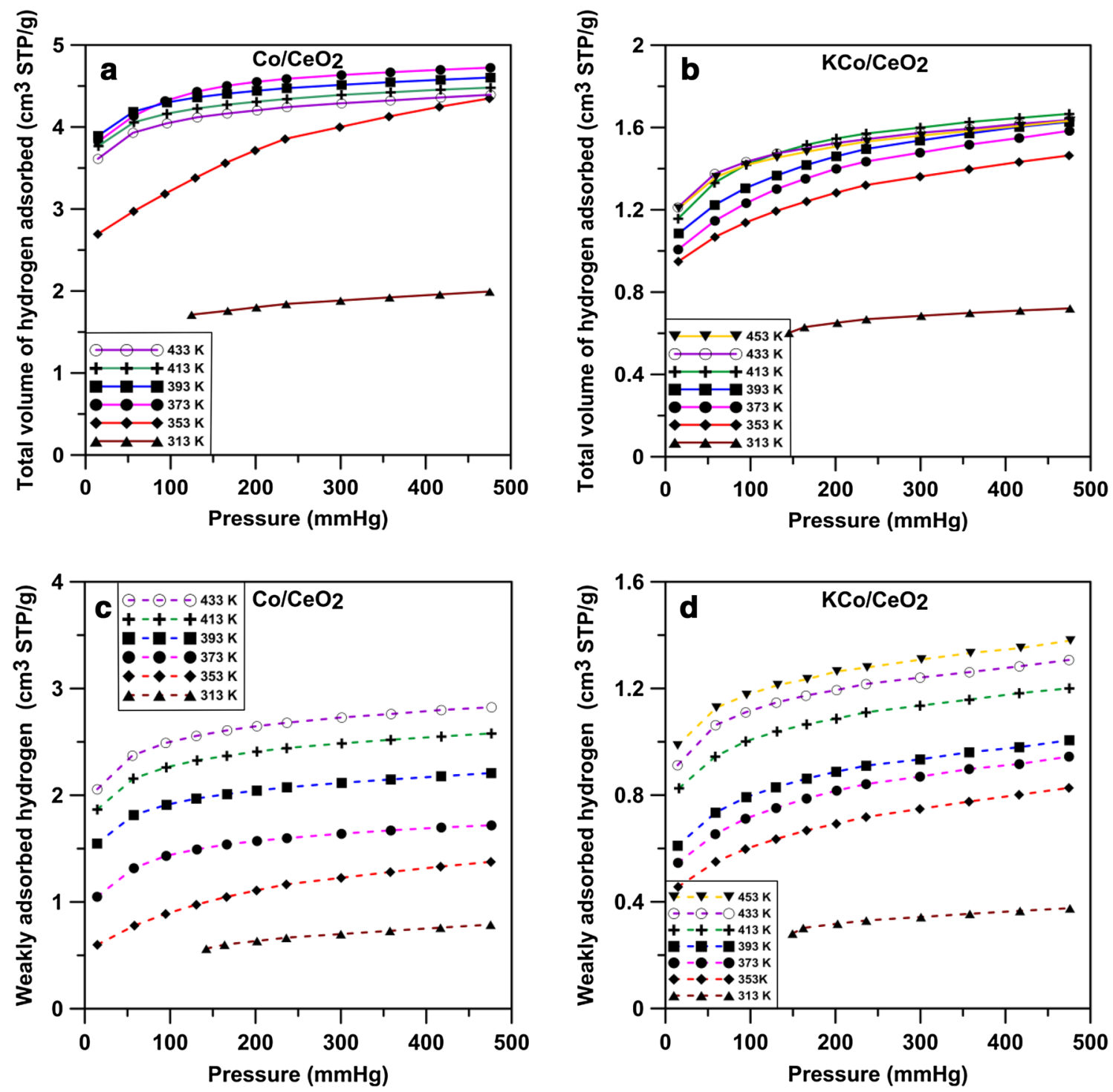

Fig. 6 Total $(\mathbf{a}, \mathbf{b})$ and weak (c, d) hydrogen chemisorption isotherms measured at various temperatures over $\mathrm{Co} / \mathrm{CeO} \mathrm{Cnd}_{\mathrm{KCo} / \mathrm{CeO}}$ catalysts pre-reduced in situ at $673 \mathrm{~K}$

STEM-EDS analysis of reduced $\mathrm{KCo} / \mathrm{CeO}_{2}$ catalyst (Fig. $3 b)$ shows good dispersion of metallic cobalt (Co, $\mathrm{Ce}+\mathrm{Co}$ maps) and very good dispersion of potassium ( $\mathrm{K}$ map). The comparison of cobalt distribution maps obtained for the fresh (Fig. 3a) and reduced (Fig. 3b) potassiumpromoted catalysts confirms that the crystallites size of the active phase increases after reduction. In the case of unpromoted catalyst, the decreasing of the size of cobalt-based phase due to the reduction was also confirmed by STEMEDS analysis (not show here).

\subsection{X-ray Study of Crystallites Size}

The crystallites sizes of the cobalt-based active phase determined on the basis of the X-ray measurements (Fig. 5) are presented in Table 2. Cobalt oxide crystallites sizes in both unpromoted and K-promoted catalysts are comparable with those determined on the basis of the TEM measurements. Also, the XRD studies showed that in the $\mathrm{KCo} / \mathrm{CeO}_{2}$ catalyst the crystallites size of the cobalt active phase in oxide form $\left(\mathrm{Co}_{3} \mathrm{O}_{4}\right)$ is much smaller than the size of crystallites in metallic form (after hydrogen reduction at $673 \mathrm{~K}$ ). An increase in the crystallites size of the active phase, from $7.1 \mathrm{~nm}$ for oxidized form $\mathrm{Co}_{3} \mathrm{O}_{4}$ to $15.2 \mathrm{~nm}$-for metallic cobalt form, was observed. Whereas, for the unpromoted catalyst $\left(\mathrm{Co} / \mathrm{CeO}_{2}\right)$ such significant change in the size of crystallites was not seen (oxide form $7.4 \mathrm{~nm}$, reduced form $7.8 \mathrm{~nm})$.

The analysis of X-ray diffraction data is known as a simple and rapid, however the results obtained for reduced catalysts were in contrast to those obtained from TEM measurements and the determined size of crystallites was not 

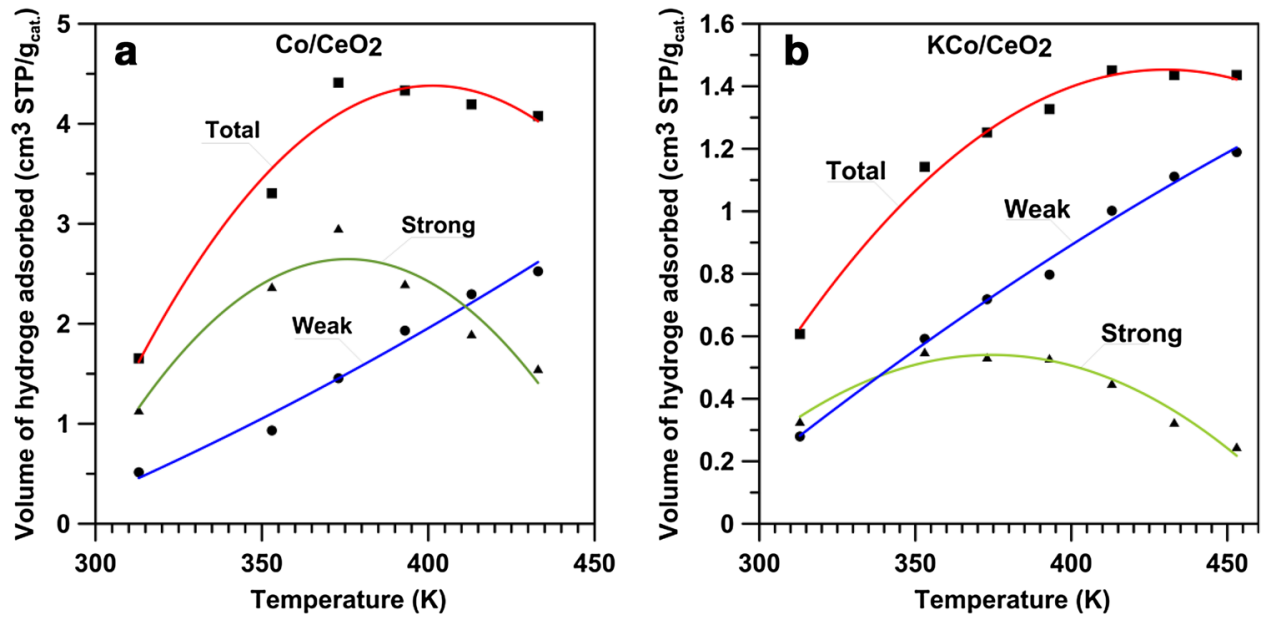

Fig. 7 Total, weak and strong hydrogen chemisorption over a $\mathrm{Co} / \mathrm{CeO}_{2}$ and $\mathbf{b} \mathrm{KCo} / \mathrm{CeO}_{2}$ catalysts, measured at various temperatures
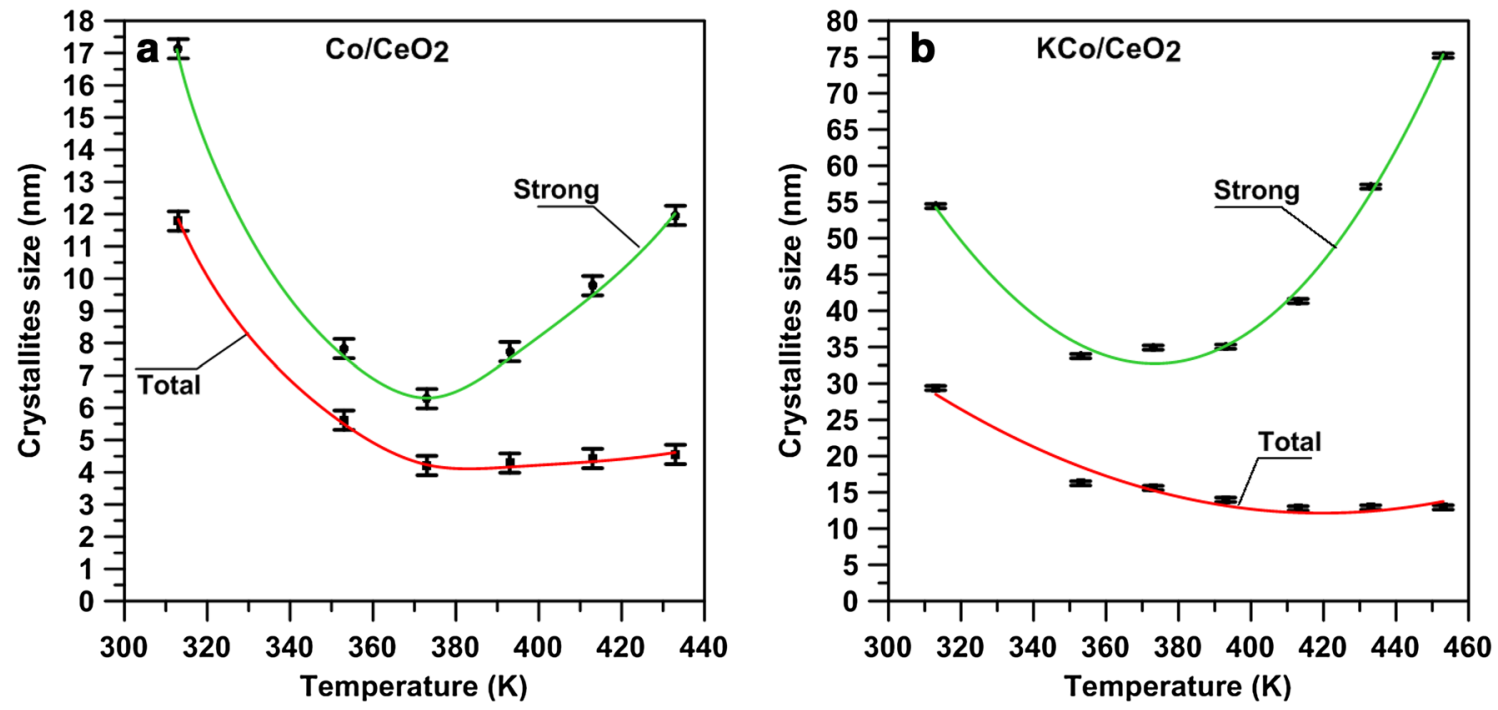

Fig. 8 Calculated average crystallites size of the Co active phase determined (calculated) from the total and strong hydrogen chemisorption data obtained at various temperatures for $\mathbf{a} \mathrm{Co} / \mathrm{CeO}_{2}$ and $\mathbf{b} \mathrm{KCo} / \mathrm{CeO}_{2}$ catalysts

very accurate. This incompatibility may results from inherent limitations in the peak profile analysis of the XRD data with the use of a width of the peak at the half of its maximum, what excludes very small crystallites from XRD data analysis [25].

\subsection{Hydrogen Chemisorption Studies}

Figure 6 shows the total and weak hydrogen chemisorption isotherms on the $\mathrm{Co} / \mathrm{CeO}_{2}$ and $\mathrm{KCo} / \mathrm{CeO}_{2}$ catalysts prereduced in-situ at $673 \mathrm{~K}$ and measured in the range of the temperature from 313 to 433 or $453 \mathrm{~K}$. With the increased temperature the isotherms become linear at lower equilibrium pressures for both samples and the amount of chemisorbed hydrogen initially increases, then goes through a maximum and finally it decreases a little at the highest temperatures. There were two adsorption isotherms recorded in each experiment, the first one includes the total hydrogen adsorption and the second one includes only weak hydrogen adsorption. The difference between these two adsorption isotherms indicates the amount of a strong hydrogen adsorption on the cobalt catalysts [39].

The amounts of the total and weak hydrogen chemisorbed and the difference between total chemisorption and weak chemisorption, i.e. hydrogen strongly chemisorbed, at each measurement temperature, for both catalysts are presented in Fig. 7. For both catalysts, in the lower temperatures range the increase of the temperature causes simultaneously increase of the total, weak and strong chemisorption. The maximum of the total chemisorption was obtained at $383 \mathrm{~K}$ for the $\mathrm{Co} / \mathrm{CeO}_{2}$ catalyst and at $413 \mathrm{~K}$ in the case of $\mathrm{KCo} / \mathrm{CeO}_{2}$ catalyst. In the case of the strong 
chemisorption the maximum of hydrogen uptake was at $373 \mathrm{~K}$ for both samples. Above the temperature of maxima of hydrogen chemisorption a small decline of the total and very clear decline of strongly adsorbed hydrogen amounts were observed. In the whole range of temperatures, weak chemisorption increased almost linearly.

Figure 8 shows the average crystallites size of metal active phase determined (calculated) on the basis of the total and strong chemisorption for $\mathrm{Co} / \mathrm{CeO}_{2}$ and $\mathrm{KCo} / \mathrm{CeO}$ catalysts. The lowest crystallites size of $6.5 \mathrm{~nm}$ for the $\mathrm{Co} / \mathrm{CeO}_{2}$ catalyst and $34 \mathrm{~nm}$ for the $\mathrm{KCo} / \mathrm{CeO}_{2}$ catalyst was determined from the strongly chemisorbed hydrogen uptake at $373 \mathrm{~K}$. Below and above this chemisorption temperature the calculated crystallites sizes are much larger. In the case of the total amount of chemisorbed hydrogen, the lowest average size of cobalt-based crystallites in the unpromoted $\mathrm{Co} / \mathrm{CeO}_{2}$ catalyst, i.e. $4.1 \mathrm{~nm}$, was calculated using the hydrogen chemisorption uptake obtained at $383 \mathrm{~K}$. For the potassium-promoted $\mathrm{KCo} / \mathrm{CeO}_{2}$ catalyst, the smallest average size of cobalt crystallites was determined from the total chemisorption of hydrogen data obtained at $413 \mathrm{~K}$. Using the total hydrogen uptake from lower temperatures the calculated average crystallites size is much higher. Above indicated temperatures of chemisorption the calculated crystallites size does not differ significantly from those obtained from maximum hydrogen uptake data. The hydrogen chemisorption studies show also that in the case of the catalyst promoted with potassium the higher temperature of hydrogen chemisorption is required to obtain the smallest crystallites size of the cobalt-based active phase.

Our comparative studies on determination of cobalt crystallites size by various methods, such as TEM, XRD and hydrogen chemisorption, show a very good correlation of results obtained with TEM and hydrogen chemisorption methods, when the total hydrogen chemisorption data obtained at $383 \mathrm{~K}$ (or at $413 \mathrm{~K}$ when the catalyst is promoted with potassium) are used for determination of the dispersion of cobalt-based active phase (Table 2).

Such temperature conditions used for hydrogen chemisorption and the total hydrogen uptake should be used for determination of the average size of cobalt-based crystallites by using of hydrogen chemisorption data. Because the difference in the size of crystallites in the unpromoted and $\mathrm{K}$-promoted catalysts estimated from the hydrogen chemisorption data obtained at 383 and $413 \mathrm{~K}$ is very small (Fig. 8) for routine studies of large number of potassiumfree and potassium-promoted catalysts, the chemisorption temperature from the range of 383-413 $\mathrm{K}$ may be also acceptable. Our results also clearly prove that the average size of cobalt crystallites determined from strongly chemisorbed hydrogen uptake is overestimated. This may be also the case of the flow adsorption methods, i.e. the pulse adsorption or the temperature-programmed desorption methods, where weakly chemisorbed hydrogen is removed from the metal surface by an inert gas before desorption measurements.

\section{Conclusions}

Comparison of the average size of the cobalt-based crystallites measured by TEM, hydrogen chemisorption and XRD methods proved that the good agreement between values obtained from total chemisorption and TEM data is possible. The total hydrogen uptake on the potassium-free catalyst, measured at $383 \mathrm{~K}$, leads to the estimation of the size of crystallites compatible with the values measured by the most objective, microscopic method. When potassium is present in the catalyst, the optimum of hydrogen chemisorption temperature is higher by c.a. $30 \mathrm{~K}$, i.e. $413 \mathrm{~K}$.

The average size of cobalt-based crystallites estimated from XRD data is congruous with that measured by the TEM method only in the case when among crystallites there are no very small ones.

Acknowledgments The research was carried out with the equipment purchased thanks to the financial support of the European Regional Development Fund in the framework of the Polish Innovation Economy Operational Program (contract no. POIG.02.01.00-06-024/09 Centre for Functional Nanomaterials; http://www.cnf.umcs.lublin.pl). All measurements presented in this article were done in the Analytical Laboratory of the Chemistry Faculty at the University of Maria CurieSklodowska accredited according to the ISO/IEC 17025:2005 international standard by the Polish Centre for Accreditation.

Open Access This article is distributed under the terms of the Creative Commons Attribution 4.0 International License (http://creativecommons.org/licenses/by/4.0/), which permits unrestricted use, distribution, and reproduction in any medium, provided you give appropriate credit to the original author(s) and the source, provide a link to the Creative Commons license, and indicate if changes were made.

\section{References}

1. Zhou W, Wachs IE, Kiely ChJ (2012) Curr Opin Struct 16:10

2. Ni M, Leung DYC, Leung MKH (2007) Int J Hydrog Energy 32:3238

3. Arsalanfar M, Mirzaei AA, Bozorgzadeh HR, Atashi H, Shahriari S, Pourdolat A (2012) J Nat Gas Sci Eng 9:119

4. Spadaro L, Arena F, Granados ML, Ojeda M, Fierro JLG, Frusteri F (2005) J Catal 234:451

5. Rybak P, Tomaszewska B, Machocki A, Grzegorczyk W, Denis A (2011) Catal Today 176:14

6. Khodakov AY, Chu W, Fongarland P (2007) Chem Rev 107:1692

7. Figen HE, Baykara SZ (2015) Int J Hydrog Energy 40:7439

8. Borodziński A, Bonarowska M (1997) Langmuir 13:5613

9. Xiong J, Borg Ø, Blekkan EA, Holmen A (2008) Catal Commun 9:2327

10. Namai Y, Fukui K, Iwasawa Y (2003) J Phys Chem B 107:11666 
11. Al-Hmoud L, Jones ChW (2013) J Catal 301:116

12. Trovarelli A, Zamar F, Llorca J, de Leitenburg C, Dolcetti G, Kiss JT (1997) J Catal 169:490

13. Lin SS-Y, Kim DH, Ha SY (2009) Appl Catal A 355:69

14. Zanchet D, Santos JBO, Damyanova S, Gallo JMR, Bueno JMC (2015) ACS Catal 5:3841

15. Haryanto A, Fernando S, Murali N, Adhikari S (2005) Energy Fuel 19:2098

16. Mattos LV, Jacobs G, Davis BH, Noronha FB (2012) Chem Rev 112:4094

17. Wang H, Wang C, Yan H, Yi H, Lu J (2015) J Catal 324:59

18. Carter JL, Cusumano JA, Sinfelt JH (1966) J Phys Chem 70:2257

19. Kępiński L (2010) Ann Univ M. Curie-Sklodowska, LXV, 2, Sect. AA: 9.

20. Kugai J, Fox EB, Song C (2015) Appl Catal A 497:31

21. Jianga X, Koizumi N, Guo X, Song Ch (2015) Appl Catal B 170-171:173

22. Aramendia MA, Borau V, Jiménez C, Marinas JM, Moreno A (1996) Colloids Surfaces A Physicochem Eng Aspects 106:161

23. Zowtiak JM, Weatherbee GD, Bartholomew CH (1983) J Catal $82: 230$

24. Zowtiak JM, Bartholomew CH (1983) J Catal 83:107.

25. Reuel RC, Bartholomew CH (1984) J Catal 85:63.

26. Bartholomew CH (1990) Catal Lett 7:27
27. Bergeret G, Gallezot P (2008) In: Ertl G, Knözinger H, Schüth F, Weitkamp J (eds) Handbook of heterogeneous catalysis. Wiley$\mathrm{VCH}$, Weinheim

28. Greluk M, Rybak P, Słowik G, Rotko M, Machocki A (2015) Catal Today 242:50

29. Banach B, Machocki A (2015) Appl Catal A 505:173

30. Yang J, Frøseth V, Chena D, Holmen A (2016) Surf Sci 648:67

31. Barrientosa J, Montes V (2015) Catal Today doi:10.1016/j. cattod.2015.10.039.

32. Wu H, Yang Y, Suo H, Qing M, Yan L, Wu B, Xu J, Xiang H, Li Y (2015) J Mol Catal A Chem 396:108

33. Rekha V, Sumana C, Douglas SP, Lingaiah N (2015) Appl Catal A 491:155

34. Zhao X, Lu G (2016) Int J Hydrog Energy 41:3349

35. Jian-Kang H, Li-Tao J, Bo H, De-Bao L, Yan L, Ya-Chun L (2015) J Fuel Chem Technol 43:846

36. Shimura K, Miyazawa T, Hanaoka T, Hirata S (2015) Appl Catal A 494:1

37. Sukkathanyawat H, Tungkamani S, Phongaksorn M, Rattana T, Narataruksa P, Yoosuk B (2015) Energy Procedia 79:372

38. Cullity BD (1978) Elements of X-ray diffraction. Addison-Wesley, London

39. Hilmen AM, Schanke D, Hanssen KF, Holmen A (1999) Appl Catal A 186:169 